MATEC Web of Conferences 47, 01013 (2016)

DOI: $10.1051 /$ matecconf/20164701013

(C) Owned by the authors, published by EDP Sciences, 2016

\title{
Effect of Pelletized Coconut Fibre on the Compressive Strength of Foamed Concrete
}

\author{
Zainorizuan Mohd Jaini ${ }^{1, a}$, Shahrul Niza Mokhatar ${ }^{1}$, Ammar Saifuddin Mohd Yusof $^{2}$, Syurafarina \\ Zulkiply $^{2}$ and Mohd Hadi Abd Rahman ${ }^{1}$ \\ ${ }^{1}$ Jamilus Research Center, Universiti Tun Hussein Onn Malaysia, 86400 Parit Raja, Johor, Malaysia \\ ${ }^{2}$ Faculty of Civil and Environmental Engineering, Universiti Tun Hussein Onn Malaysia, 86400 Parit Raja, Johor, \\ Malaysia
}

\begin{abstract}
Foamed concrete is a controlled low density ranging from $400 \mathrm{~kg} / \mathrm{m}^{3}$ to $1800 \mathrm{~kg} / \mathrm{m}^{3}$, and hence suitable for the construction of buildings and infrastructures. The uniqueness of foamed concrete is does not use aggregates in order to retain low density. Foamed concrete contains only cement, sand, water and foam agent. Therefore, the consumption of cement is higher in producing a good quality and strength of foamed concrete. Without the present of aggregates, the compressive strength of foamed concrete can only achieve as high as $15 \mathrm{MPa}$. Therefore, this study aims to introduce the pelletized coconut fibre aggregate to reduce the consumption of cement but able to enhance the compressive strength. In the experimental study, forty-five (45) cube samples of foamed concrete with density $1600 \mathrm{~kg} / \mathrm{m}^{3}$ were prepared with different volume fractions of pelletized coconut fibre aggregate. All cube samples were tested using the compression test to obtain compressive strength. The results showed that the compressive strength of foamed concrete containing $5 \%, 10 \%, 15 \%$ and $20 \%$ of pelletized coconut fibre aggregate are $9.6 \mathrm{MPa}, 11.4 \mathrm{MPa}, 14.6 \mathrm{MPa}$ and $13.4 \mathrm{MPa}$ respectively. It is in fact higher than the controlled foamed concrete that only achieves 9MPa. It is found that the pelletized coconut fibre aggregate indicates a good potential to enhance the compressive strength of foamed concrete.
\end{abstract}

\section{Introduction}

Foamed concrete has received high attention in the construction industry due to its advantageous of lightness and versatility material. The primary characteristic of foamed concrete is cement based mortar that consist at least $20 \%$ of air voids. Therefore, foamed concrete has low density, good strength and reliable toughness at minimal consumption of aggregate. Typically, foamed concrete can achieve dry density in the range of $400 \mathrm{~kg} / \mathrm{m}^{3}$ to $1600 \mathrm{~kg} / \mathrm{m}^{3}$ with compressive strength around $1 \mathrm{MPa}$ to $15 \mathrm{MPa}[1,2]$. The tensile strength of foamed concrete is directly proportion of its compression strength and lower approximately ten times. Meanwhile, the fracture energy of foamed concrete is around $15 \mathrm{~N} / \mathrm{m}$ to $35 \mathrm{~N} / \mathrm{m}$ [3-5]. Although a comparison with normal concrete shows that the strength of foamed concrete is slightly lower. Still, there are demands on the application of foamed concrete as construction material and structural element.

\footnotetext{
${ }^{a}$ Corresponding author : rizuan@uthm.edu.my
} 
Since the strength of foamed concrete is lower than normal concrete, many attempts have been made to enhance the ability of foamed concrete in carrying meaningful actions. Such attempts include the utilization of supplementary cementitious materials such as rice husk ash, palm oil ash, artificial fibres and natural reinforcements. The fascination toward green and sustainable material in construction industry has prompted the use of natural reinforcements such as coconut and kenaf fibres. Moreover, foamed concrete containing natural reinforcement is an attractive option. Normally, in concrete, steel or polypropylene fibre is used to increase the strength, but it can also increase the weight and cost of the concrete. Therefore, the application of natural fibre is one of the alternatives due to high availability and environmental friendly.

\section{Concrete Containing Coconut Fibre}

In recent years, the use of coconut fibre as reinforcement on concrete has received high attention because of renewability, low density, high specific properties and low cost. High specific properties include the strength, lightness, stiffness, impact resistance and flexibility [6]. Moreover, coconut fibre in concrete also has become an interesting application towards sustainable construction. Based on an experimental study by Ruben and Braker [7], it was found that concrete containing coconut fibre not just bring several improvement in concrete characteristics but also reduces environment pollution factors. Savastano and Agopyan [8] reported that the combination of short coconut fibres with ordinary Portland cement has presented a significant increase in toughness. Several factors such as properties, volume fraction, distribution and orientation of fibre are identified to be influenced the physical and mechanical properties of concrete. However, the volume fraction appears to be the most dominant factor in influencing the strength of concrete.

The application of concrete containing coconut fibre as structural elements was study by Ali [9]. The study on the behaviour of coconut fibre-concrete columns reveals that non-visible degradation occur prior to the cracking of the column. The use of coconut fibre in cement has increased the flexural strength and consequence improves the crack resistance. Coconut fibre alters the behaviour of concrete when cracks occur across the structure and thus can provide a residual strength of the concrete [10]. Therefore, concrete containing coconut fibre exhibits same performance as that of conventional reinforced concrete produced by steel fibre [11]. In addition, the compressive of strength is also improved up to a certain percentage. Baruah and Talkudar [12] investigated the mechanical properties of concrete containing coconut fibre with different volume fractions ranging from $0.5 \%$ to $2 \%$. From the obtained results, it is found that $1.5 \%$ of volume fraction of coconut fibre produce optimum strength with increment of $14.66 \%$. A summary of studies about concrete containing coconut fibre is shown in Table 1.

Table 1. Effect of coconut fibre on the strength of concrete.

\begin{tabular}{clccc}
\hline No. & \multicolumn{1}{c}{ Reference } & $\begin{array}{c}\text { Length of Fibre } \\
(\mathbf{m m})\end{array}$ & $\begin{array}{c}\text { Optimum Contain } \\
\mathbf{( \% )}\end{array}$ & $\begin{array}{c}\text { Increment of } \\
\text { Strength (\%) }\end{array}$ \\
\hline 1 & Baruah and Talkudar [12] & 40 & 1.5 & 14.66 \\
2 & Abdullah et al. [13] & - & 9.0 & 26.96 \\
3 & Domke [14] & $50-110$ & 3.0 & 16.50 \\
4 & Ruben and Baskar [15] & 30 & 1.0 & 20.59 \\
5 & Adisa et al. [16] & 82 & 1.0 & 6.70 \\
6 & Mydin et al. [17] & 34 & 0.4 & 21.00 \\
\hline
\end{tabular}




\section{Experimental Study}

\subsection{Material preparation}

Main mix proportion consists of cement, sand, foam agent and water. The density of foamed concrete is $1600 \pm 5 \mathrm{~kg} / \mathrm{m}^{3}$. Therefore, water-cement ratio and cement-sand ratio were set up at 0.55 and 0.5 respectively. Table 2 shows the mix proportion of raw materials. The brown coconut coir was used to produce pelletized coconut fibre aggregate. The coconut coir was compressed into bar with diameter approximately $5 \mathrm{~mm}$ and thin-coated using epoxy. The bar then cut into pellets with size of $10 \mathrm{~mm}$ to $20 \mathrm{~mm}$. Figure 1 shows the pelletized coconut fibre aggregate.

Table 2. Mix proportion of foamed concrete.

\begin{tabular}{ccc}
\hline Material & Ratio & Mass $(\mathbf{k g})$ \\
\hline Cement & 1.00 & 33.00 \\
Sand & 2.00 & 66.00 \\
Water & 0.55 & 18.15 \\
Foam agent & - & 26.00 \\
\hline
\end{tabular}

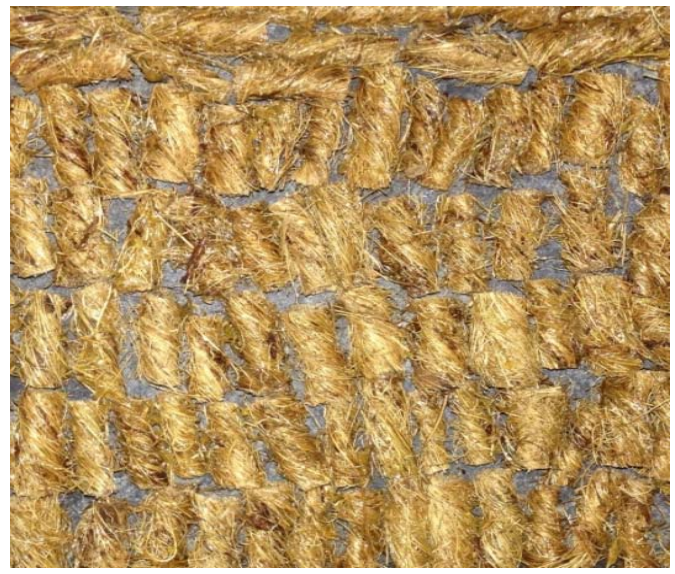

Figure 1. Pelletized coconut fibre aggregate.

Meanwhile, three (3) samples of coconut coir bars were tested under tensile loading to determine the tensile strength and Young's modulus. The results from the test, as shown in Figure 2, gave the average tensile strength and Young's modulus around 3.785MPa and $0.079 \mathrm{GPa}$ respectively.

\subsection{Specimen preparation}

In the experimental study, forty-five (45) cube specimens were prepared for the compression test. Thirty-six (36) of the cube specimens are foamed concrete containing different volume fractions of pelletized coconut fibre aggregate at 5\%,10\%,15\% and 20\%. Another nine (9) cube specimens were cast for the controlled foamed concrete. Table 3 shows the specification of cube specimens. All cube specimens were placed at the ambient condition for the air curing process at 7, 14 and 28 days before the compression test take place. Figure 3 shows the curing process of the cube specimens and the compression test. 


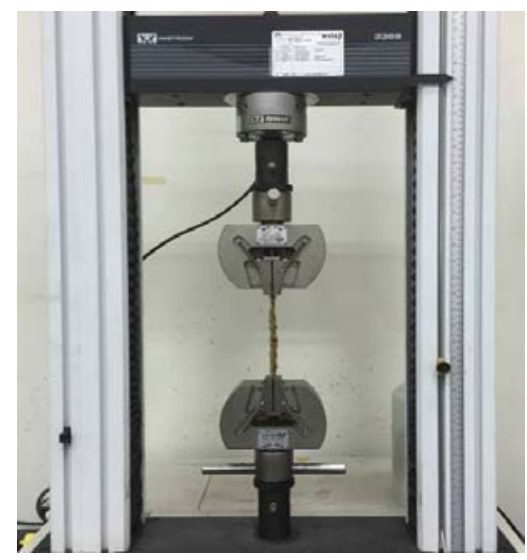

a) Experimental setup

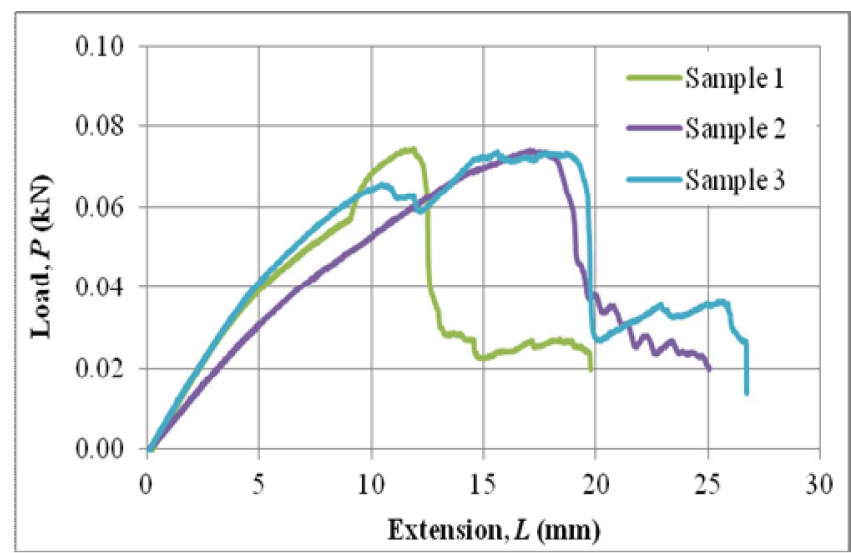

b) Tensile strength of coconut fibre bars

Figure 2. Tensile test of coconut fibre bars.

Table 3. Specification of cube specimens for the compression test.

\begin{tabular}{ccccccc}
\hline \multirow{2}{*}{ No. } & Specimen & \multicolumn{4}{c}{ Percentage of Pellet (\%) } & \multicolumn{4}{c}{ Quantity of Cube Specimen } \\
\cline { 4 - 7 } & & 0 & $\mathbf{7}$ days & $\mathbf{1 4}$ days & $\mathbf{2 8}$ days & Total \\
\hline 1 & FC-A00 & 5 & 3 & 3 & 3 & 9 \\
2 & FC-B05 & 10 & 3 & 3 & 3 & 9 \\
3 & FC-C10 & 15 & 3 & 3 & 3 & 9 \\
4 & FC-D15 & 20 & 3 & 3 & 3 & 9 \\
5 & FC-E20 & & Total & & & 45 \\
\hline
\end{tabular}

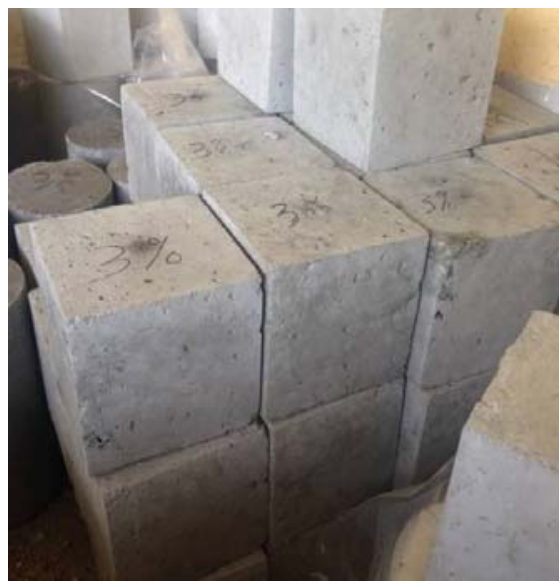

a) Air-curing process

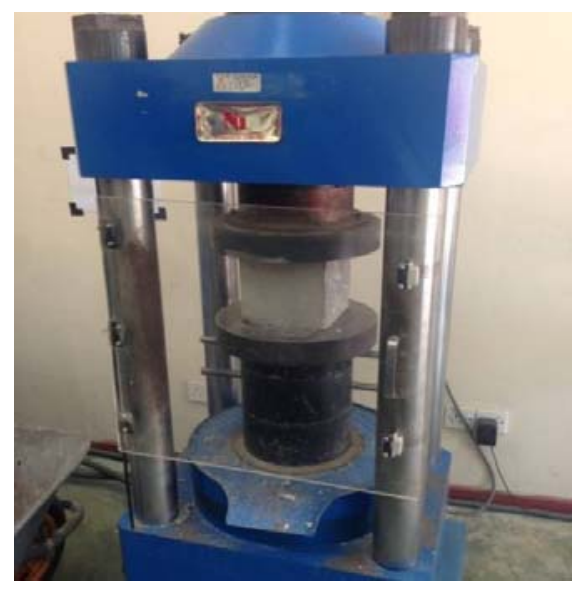

b) Compression test

Figure 3. Curing process and compression test of cube specimens at 7, 14 and 28 days. 


\section{Results and Discussion}

The compressive strength of foamed concrete containing pelletized coconut fibre aggregate along with dry density and standard deviation are given in Table 4 . The average compressive strength of controlled foamed concrete at 28 days is $9.0 \mathrm{MPa}$. In accordance with Jaini et al. [2] and Aldridge [18], the compressive strength of foamed concrete with density of $1600 \mathrm{~kg} / \mathrm{m}^{3}$ is in the range of $7.5 \mathrm{MPa}$ to 10.0MPa. Therefore, the controlled foamed concrete showed good agreement and convincing compressive strength.

Table 4. Dry density and compressive strength of cube specimens.

\begin{tabular}{|c|c|c|c|c|c|c|}
\hline \multirow{2}{*}{ Specimen } & \multirow{2}{*}{$\begin{array}{l}\text { Dry Density } \\
\quad\left(\mathrm{kg} / \mathrm{m}^{3}\right)\end{array}$} & \multirow{2}{*}{$\begin{array}{c}\text { Curing Age } \\
\text { (days) }\end{array}$} & \multicolumn{3}{|c|}{ Compressive Strength (MPa) } & \multirow{2}{*}{$\begin{array}{c}\text { Standard } \\
\text { Deviation } \\
(\sigma)\end{array}$} \\
\hline & & & Specimen 1 & Specimen 2 & Specimen 3 & \\
\hline \multirow[t]{3}{*}{ FC-A00 } & 1611.85 & 7 & 6.0 & 6.2 & 6.1 & 0.100 \\
\hline & 1605.93 & 14 & 8.0 & 7.8 & 8.2 & 0.200 \\
\hline & 1602.96 & 28 & 9.0 & 9.2 & 8.8 & 0.400 \\
\hline \multirow[t]{3}{*}{ FC-B05 } & 1608.89 & 7 & 7.4 & 7.5 & 7.3 & 0.100 \\
\hline & 1605.93 & 14 & 8.9 & 8.7 & 9.0 & 0.150 \\
\hline & 1600.10 & 28 & 9.8 & 9.5 & 9.6 & 0.100 \\
\hline \multirow[t]{3}{*}{ FC-C10 } & 1602.96 & 7 & 9.0 & 9.1 & 9.0 & 0.050 \\
\hline & 1600.96 & 14 & 10.5 & 10.3 & 10.1 & 0.200 \\
\hline & 1596.23 & 28 & 11.5 & 11.9 & 10.9 & 0.500 \\
\hline \multirow[t]{3}{*}{ FC-D15 } & 1600.21 & 7 & 9.5 & 9.7 & 9.3 & 0.200 \\
\hline & 1597.04 & 14 & 11.5 & 11.3 & 11.8 & 0.250 \\
\hline & 1586.00 & 28 & 14.3 & 15.0 & 14.5 & 0.350 \\
\hline \multirow[t]{3}{*}{ FC-E20 } & 1593.15 & 7 & 8.5 & 8.6 & 8.8 & 0.150 \\
\hline & 1585.03 & 14 & 10.9 & 10.5 & 11.3 & 0.400 \\
\hline & 1580.21 & 28 & 13.7 & 13.0 & 13.5 & 0.350 \\
\hline
\end{tabular}

Meanwhile, the average compressive strength of foamed concrete containing $5 \%, 10 \%, 15 \%$ and $20 \%$ of pelletized coconut fibre aggregate are $9.6 \mathrm{MPa}, 11.4 \mathrm{MPa}, 14.6 \mathrm{MPa}$ and $13.4 \mathrm{MPa}$ respectively. The pattern of compressive strength due to the volume fraction of pelletized coconut fibre aggregate at 7, 14 and 28 days is shown Figure 4. It can be observed that by increasing the volume fraction of pelletized coconut fibre aggregate on foamed concrete, the compressive strength is escalated significantly. Among the specimens, foamed concrete containing $15 \%$ pelletized coconut fibre aggregate showed the highest compressive strength. There is $62.22 \%$ of strength increment, as can be referred in Figure 5, compared with that obtained by controlled foamed concrete. Although foamed concrete containing $15 \%$ pelletized coconut fibre aggregate has achieved significant increment of compressive strength, however, it is still insufficient for structural application. A comparison with previous studies indicate that the pelletized coconut fibre is sustainable and effective in improving the compressive strength of foamed concrete with high utilization of volume fraction. This condition can contribute to the great saving of cement and consequently promote green concrete in the construction industry. In addition, it is also found that the use of pelletized coconut fibre aggregate tends to reduce the dry density of foamed concrete. 


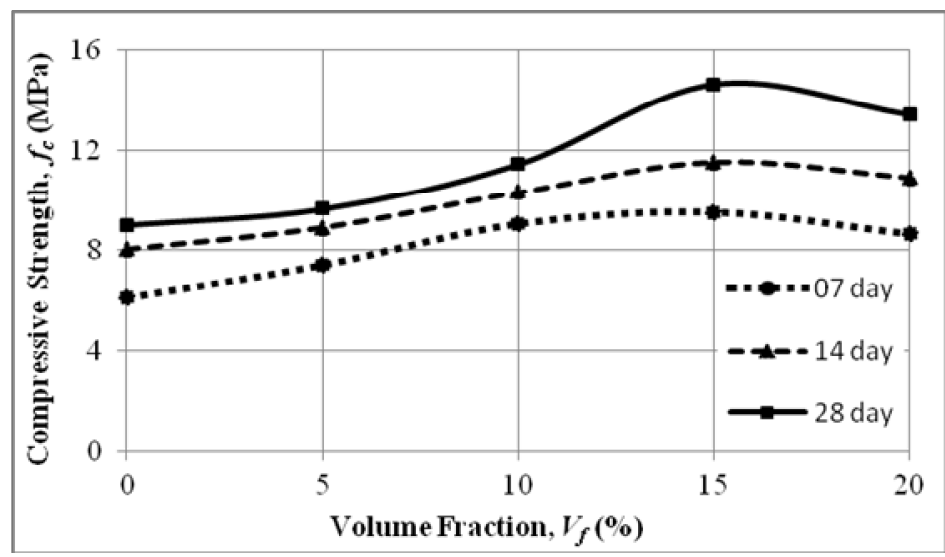

Figure 4. Strength development of foamed concrete based on volume fraction of aggregate.

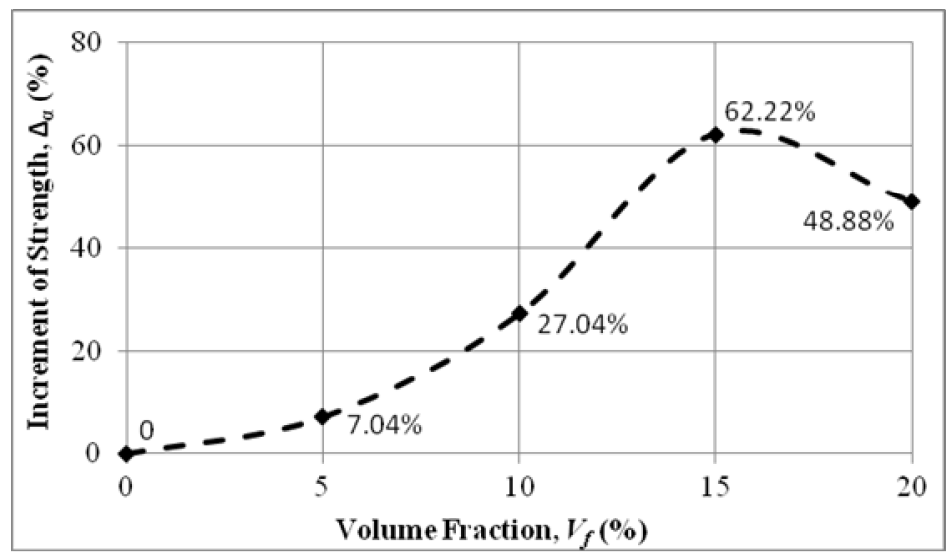

Figure 5. Strength increment of foamed concrete based on volume fraction of aggregate.

\section{Conclusions}

The study on the effect of pelletized coconut fibre aggregate on the strength of foamed concrete was conducted by using the compression test. The results showed that the compressive strength increases significantly until optimum volume fraction of $15 \%$. It is found that the pelletized fibre aggregate indicates a good potential to enhance the compressive strength of foamed concrete. However, other characteristics of fresh and harden concrete need further investigations.

\section{References}

[1] M.R. Jones and A. McCarthy, Preliminary views on the potential of foamed concrete as a structural materials, Magazine of Concrete Research, 7(1), 21-31,(2005).

[2] Z.M. Jaini, S.N. Mokhatar, Y.T. Feng and M.A. Seman, 2D multi-scale modelling of foamed concrete containing rubber bars, Proc. of the Int. Civil and Infrastructure Engineering Conference, Springer, Singapore, 625-638, (2015).

[3] N. Abd Rahman, Z.M. Jaini, N.A. Abd Rahim and S.A. Abd Razak, An experimental study on the fracture energy of foamed concrete using v-notched beams, Proc. of the Int. Civil and Infrastructure Engineering Conference, Springer, Singapore, 97-108, (2015). 
[4] M. Kozlowski, M. Kadela and A. Kukielka, Fracture energy of foamed concrete based on threepoint bending test on notched beams, Procedia Engineering, 108, 349-354, (2015).

[5] N. Abd Rahman, Z.M. Jaini and N.N.M. Zahir, Fracture energy of foamed concrete by means of the three-point bending test on nocthed beam specimens, ARPN J. of Engineering and Applied Sciences, 10(15), 6562-6570, (2015).

[6] N. Sgriccia, M.C. Hawley and M. Misra, Characterization of natural fiber surface and natural fibre composites, Composite Part A: Applied Science and Manufacturing, 39(10), 1632-1637, (2008).

[7] J.S. Ruben and G, Baskar, Experimental study of coir fiber as concrete reinforcement material in cement based composites, J. of Engineering Research and Application, 4(1), 128-131, (2014).

[8] J.H. Savastano and V. Agopyan, Transition zone studies of vegetable fibre-cement past composites, Cement and Concrete Composites, 21, 49-57, (1999).

[9] M. Ali, Seismic performance of coconut fibre-reinforced-concrete columns with different reinforcement configurations of coconut-fibre ropes, Construction and Building Material, 70, 226-230, (2014).

[10]M. Ali, X. Li and N. Chouw, Experimental investigations on bond strength between coconut fibre and concrete, Material and Design, 44, 596-605, (2013).

[11]K. Bilba, M. Arsene and A. Ouensanga, Study on banana and coconut fibers botanical composition, thermal degradation and textural observations, Bioresource Technology, 98(1), 58-68, (2007).

[12]P. Baruah and S.A. Talkudar, Comparatuve study of compressive, flexural, tensile and shear strength of concrete with fibres of different originis, Indian Concrete J., 81(7), 17-24, (2007).

[13] A. Abdullah, S. Jamaluddin and M. Anwar, Assessment of physical and mechanical properties of cement panel influenced by treated and untreated coconut fiber addition, Physics Procedia, 22, 262-269, (2011).

[14]P.V Domke, improvement in the strength of concrete by using industrial and agricultural waste, IOSR J. of Engineering, 2(4), 755-759, (2012).

[15]J.S. Ruben and G. Baskar, Experimental study of coir fiber as concrete reinforcement material incement based composites, Int. J. of Engineering Research and Applications, 4(1), 128-131, (2014).

[16]K.A. Olonade, A.D. Alake and A.G. Morakinyo, Strength development and crack pattern of coconut fibre reinforced strength development and crack pattern of coconut fibre reinforced, Civil and Environmental Research, 4, 46-53, (2013).

[17] M.A.OMydin, N.A. Rozlan and S. Ganesan, Experimental study on the mechanical properties of coconut fibre reinforced lightweight foamed concrete, J. Material and Environmental Sciences, 6(2), 407-411, (2015).

[18]D. Aldridge, Introduction to Foamed Concrete: Use of Foamed Concrete in Construction, Thomas Telford, London, United Kingdom, (2005). 